\title{
Docilidade Ambiental: um guia para incentivar o debate sobre um ambiente universitário acessível e ergonômico
}

\section{Environmental docility: a guide to encourage discussion about an accessible and ergonomic environment in university}

\author{
CYNTHIA TATIANE LIMA \\ Graduanda em Arquitetura e Urbanismo, CAU/UFRN, cynthia.arqurb17@gmail.com \\ LUCIANA MEDEIROS \\ Dra., CAU-PPAPMA/UFRN, medeiros.luciana@outlook.com \\ RENATO MEDEIROS \\ Dr., CAU-PPAPMA/UFRN, renatomedeirosarquitetura@gmail.com \\ GLEICE AZAMBUJA ELALI \\ Dra., CAU-PPGAU-PPAPMA/UFRN, gleiceae@gmail.com
}

\section{RESUMO}

Esse artigo apresenta uma cartilha elaborada por um grupo de pesquisa da Universidade Federal do Rio Grande do Norte (UFRN) com o objetivo de incentivar a discussão sobre alguns aspectos ligados à docilidade ambiental no campus universitário. Na cartilha são trabalhados aspectos que, nas investigações conduzidas pelos pesquisadores do grupo envolvidos na proposta, têm se tornado evidentes como elementos mais fortemente relacionados à acessibilidade integral e à qualidade de vida em campi universitários. $O$ texto aqui apresentado esclarece o conceito de docilidade ambiental (que foi escolhido para direcionar a proposta desenvolvida), delineia as algumas das características da cartilha, elenca os principais temas tratados e tece reflexões genéricas sobre a temática trabalhada.

PALAVRAS-CHAVE: docilidade ambiental, universidade, acessibilidade integral.

\begin{abstract}
This article presents a guide prepared by a UFRN research group with the aim of fostering the discussion on aspects related to 'environmental docility on campus'. It deals with aspects that, in the investigations conducted by the researchers involved, have been shown to be elements strongly related to integral accessibility and quality of life on campi. This text clarifies the concept of environmental docility (chosen to direct the proposal), outlines the main characteristics of the booklet, lists the main themes treated and weaves some general reflections on the theme.
\end{abstract}

KEYWORDS: environmental docility, university, integral accessibility. 


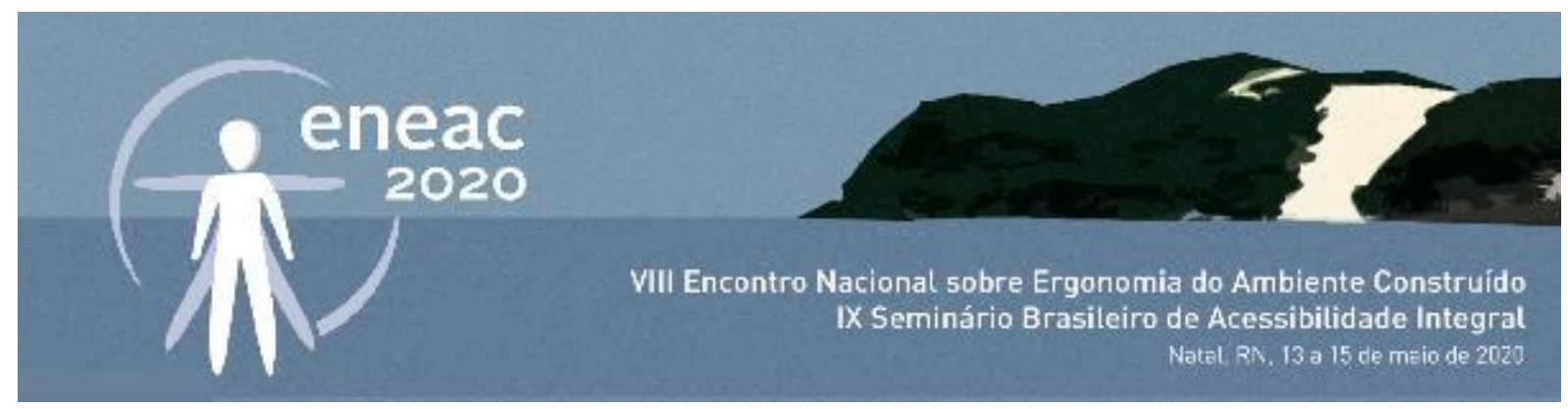

\section{INTRODUÇÃO}

O campus universitário é uma parte da cidade que congrega praticamente todas as funções urbanas: trabalho, estudo, moradia, alimentação, serviços, prática de exercícios, lazer. Como a comunidade acadêmica passa grande parte do tempo na área do campus, a qualidade de vida destas pessoas é diretamente influenciada pelas condições ambientais ali presentes, sobretudo quando partilhamos o ideal de uma universidade democrática e inclusiva.

No contexto da promoção de uma Universidade Federal do Rio Grande do Norte (UFRN) social e ambientalmente mais adequada aos seus usuários, a Comissão Permanente de Apoio a Estudantes com Necessidades Educacionais Especiais (CAENE/UFRN, atual Secretaria de Inclusão e Acessibilidade - SIA) tem produzido e divulgado cartilhas sobre temáticas ligadas à acessibilidade integral, discutindo assuntos como 'Deficiência auditiva e surdez', 'Audiodescrição' e 'Condições de acessibilidade do ambiente físico', material publicado em uma biblioteca digital de acesso livre e gratuito (http://bibliotecadigital.sedis.ufrn.br/interativos.php).

Em 2019 nosso grupo de pesquisa se propôs a elaborar uma cartilha (a ser divulgada em formato digital e lançada no primeiro semestre de 2020) cujo objetivo é fomentar o debate sobre aspectos ligados à docilidade ambiental em um campus universitário (LIMA et al, 2020). Nela trabalhamos aspectos que, em nossas pesquisas, têm se evidenciado como elementos fortemente relacionados à acessibilidade integral e, portanto, à qualidade de vida em campi. O presente artigo relata brevemente a atividade realizada e apresenta um resumo do resultado obtido. Inicialmente o texto esclarece o conceito de docilidade ambiental, que foi escolhido para direcionar a proposta; em seguida são delineadas as principais características do material produzido e elencados os principais temas tratados no guia (itens ilustrados por meio de algumas das páginas elaboradas); finalizando são tecidas algumas reflexões genéricas sobre o processo de produção da cartilha em questão.

\section{DOCILIDADE AMBIENTAL}

O conceito que permeia e justifica o trabalho realizado é o de docilidade ambiental, discutido a partir da perspectiva da Psicologia Ambiental, área do conhecimento dedicada à compreensão das relações que se estabelecem entre as pessoas e o ambiente (GÜNTHER, PINHEIRO, GUZZO, 2004; PINHEIRO, GÜNTHER, 2008; CAVALCANTE, ELALI, 2011; 2018), com valorização de seus aspectos subjetivos e comportamentais.

Segundo a literatura na área, cada pessoa tem um nível de demanda ambiental, o qual está associado ao adequado desempenho de suas atividades e às situações de conforto correlacionadas ao mesmo. Sob esse ponto de vista, é possível inferir que o desenvolvimento de comportamentos adaptativos e de afeto positivo vinculados ao local estão relacionados à congruência entre as demandas ambientais sobre o indivíduo e às condições desse indivíduo (suas habilidades e possibilidades) para lidar com as diferentes situações que surjam (GUNTHER, 2011; MOORE, 2005).

Pensando nisso, Lawton e Nahemow (1973) emitiram o conceito de docilidade ambiental, de acordo com o qual "quanto menos competente for a pessoa, maior é o impacto dos fatores ambientais sobre ela", ou seja, pessoas com habilidades reduzidas tendem a ser mais influenciadas pelas dificuldades presentes no ambiente pois dispõem um menor repertório de elementos que as auxiliem a enfrentar 


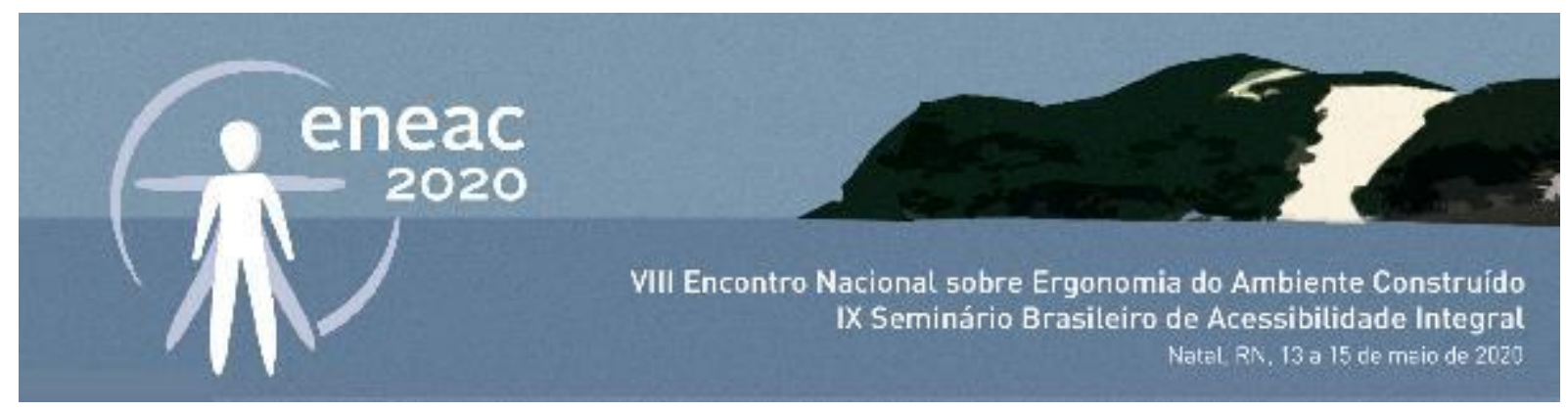

eventuais problemas. Ou seja, o ambiente 'dócil' maximiza o uso das capacidades individuais, permitindo que cada pessoa atue em sua melhor zona de desempenho (LAWTON, DEVOE, PARMELEE, 1995). Para que se verifique um melhor desempenho contribuem tanto as características do ambiente (possibilidades para deslocamento, usabilidade e orientação) quanto as condições psicossociais (aceitação e apoio do grupo).

Embora inicialmente a noção de docilidade ambiental tenha sido trabalhada no contexto da gerontologia ambiental, gradativamente o conceito está migrando para outros campos do conhecimento e tem sido utilizado em outras fases do ciclo de vida (GUNTHER, ELALI, 2011). Em algumas de suas investigações, nosso grupo de pesquisa tem utilizado o conceito de docilidade ambiental no contexto de campi universitários, verificando-se que, tanto quanto as condições do ambiente físico, o ambiente social é fundamental para o bem estar de cada pessoa ali presente. Tal tipo de constatação indica ser preciso que todos os envolvidos estejam constantemente atentos às características de conforto e acessibilidade dos ambientes que utilizam e que, além disso, é fundamental que as pessoas se tornem mais conscientes do modo como se relacionam com as demais e até consigo mesmas.

Sob esse ponto de vista, a cartilha elaborada chama a atenção para algumas questões de docilidade ambiental em campi, indicando a importância de:

(i) entende-las detalhadamente com base nas necessidades de cada indivíduo;

(ii) enfrenta-las a partir de três pontos de vista: o ambiente, a atitude do grupo e a postura/comportamento da pessoa envolvida.

\section{CARACTERÍSTICAS DA CARTILHA}

Antes de outras informações é preciso indicar que, por motivos técnicos, optou-se por produzir um material com página base em formato quadrangular, considerado mais adequado a reprodução do material em vários tipos de mídia digital (como computadores, tablets e telefones celulares). Além disso, no caso de ser manuseada como um livro digital, o leitor poderá optar por ver duas páginas simultaneamente, o que implica em um formato retangular que pode ocupar telas de maiores dimensões.

Para elaboração do material a ser manuseado pelos leitores foi criada uma personagem em torno da qual se concentram as ações, e com a qual o leitor-estudante pudesse se identificar facilmente: a Tati (Figura 1), uma estudante que passa grande parte do seu dia no campus.

Sendo usuária de muitos dos ambientes disponíveis naquele local, entende-se que Tati está em permanente contato com as condições ambientais existentes e com os diferentes tipos humanos que ali convivem, o que possibilitou tecermos comentários sobre várias situações da vida cotidiana no campus, notadamente no que diz respeito às condições necessárias à sua acessibilidade integral. Os diferentes assuntos foram derivados das pesquisas realizadas pelo grupo no campus, em especial os orientandos de mestrado e doutorado.

A cada tema tratado, além de imagens e textos que demonstram as atividades de Tati, são apresentados quadros que sintetizam condições que garantiriam maior docilidade e tornariam as 


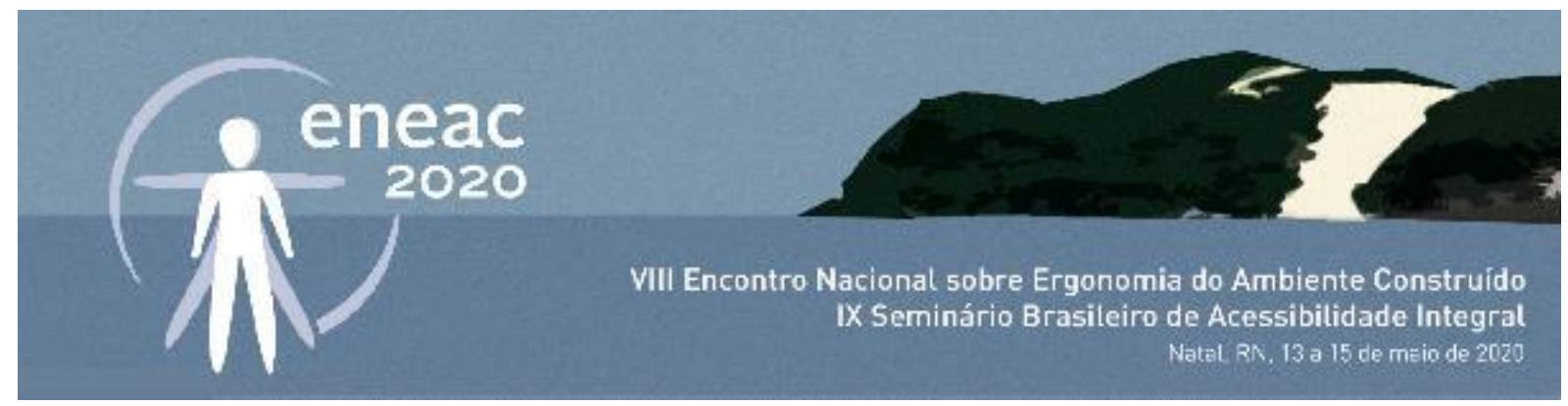

situações relatadas mais adequadas àquela pessoa e, em consequência, à comunidade como um todo. É preciso ressaltar, antecipadamente, três aspectos importantes a serem levados em consideração:

- as situações relatadas são hipotéticas, embora tenham sido criadas a partir da observação da realidade;

- apenas quando todos puderem participar e se sentirem acolhidos, nossa sociedade terá atingido condições mínimas de bem-estar coletivo;

- a docilidade ambiental não é uma condição isolada, ela depende da ação de todos.

Figura 1: Imagem ilustrativa da cartilha (página 7)

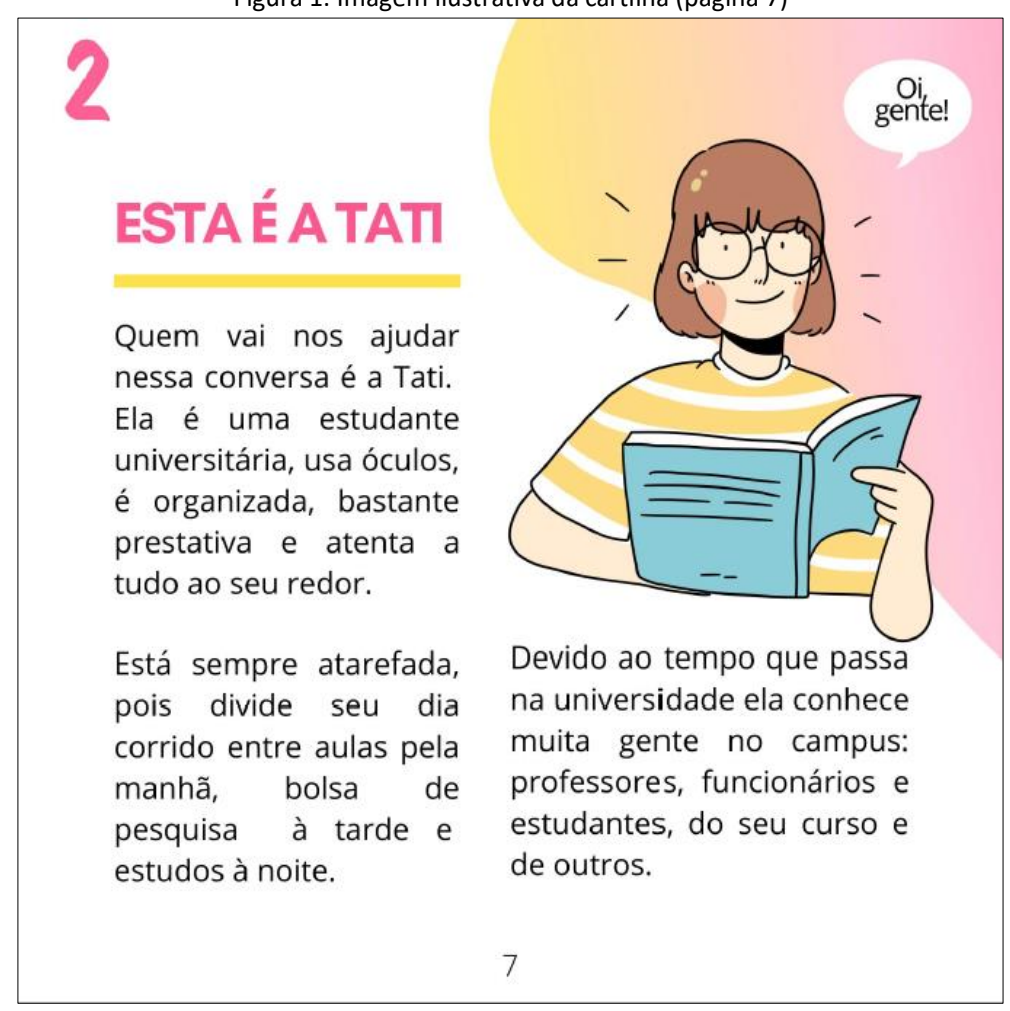

Fonte: Lima et al, 2020.

A fim de deixar a leitura mais leve e, ao mesmo tempo, não omitir elementos técnicos relativos aos assuntos tratados, foi promovido o contato simultâneo do leitor com dois tipos de informação, conforme pode ser observado na Figura 2:

(i) fatos do cotidiano apresentados de modo leve, por meio de linguagem coloquial e de desenhos - imagens que foram elaboradas pelo ilustrador Júlio Azevedo, também estudante do CAU/UFRN;

(ii) questões técnicas e do comportamento de grupo que são correlatas ao fato apresentado, apontando normas na área a serem consultadas ou cuidados genéricos a serem seguidos 


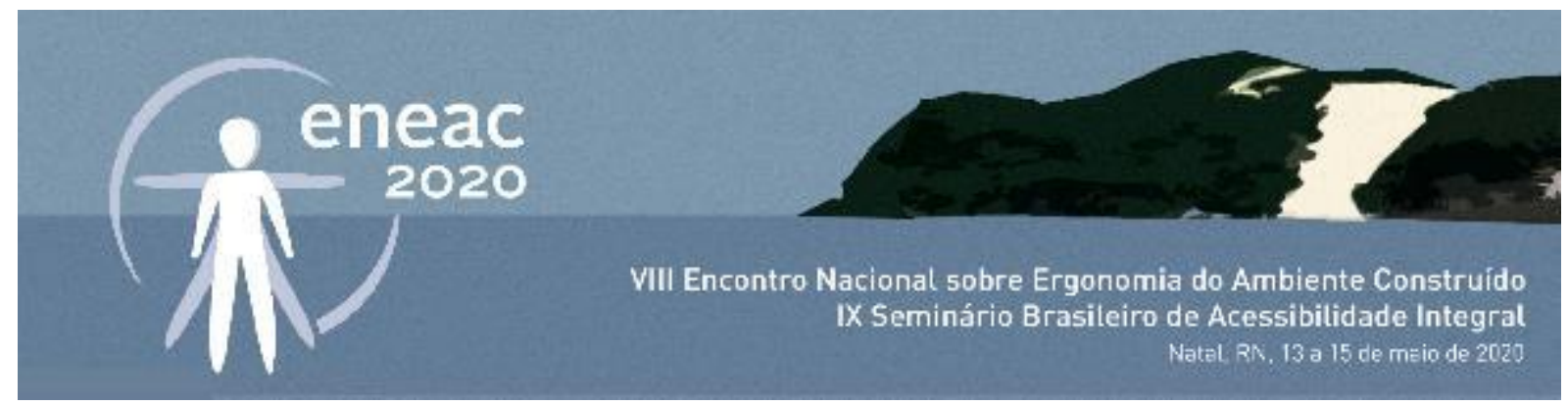

pelos envolvidos - este tipo de dados são indicados em caixa específica, destacada da imagem por se apresentar na cor cinza.

Em seu conjunto a cartilha é formada por 42 páginas, nas quais são trabalhados diversos assuntos ligados à vida em um campus universitário genérico. Também é importante salientar que, em sua versão final (digital), a cartilha disponibiliza audiodescrição e tradução para libras, em função do acionamento de links específicos.

Figura 2: Imagem ilustrativa da cartilha

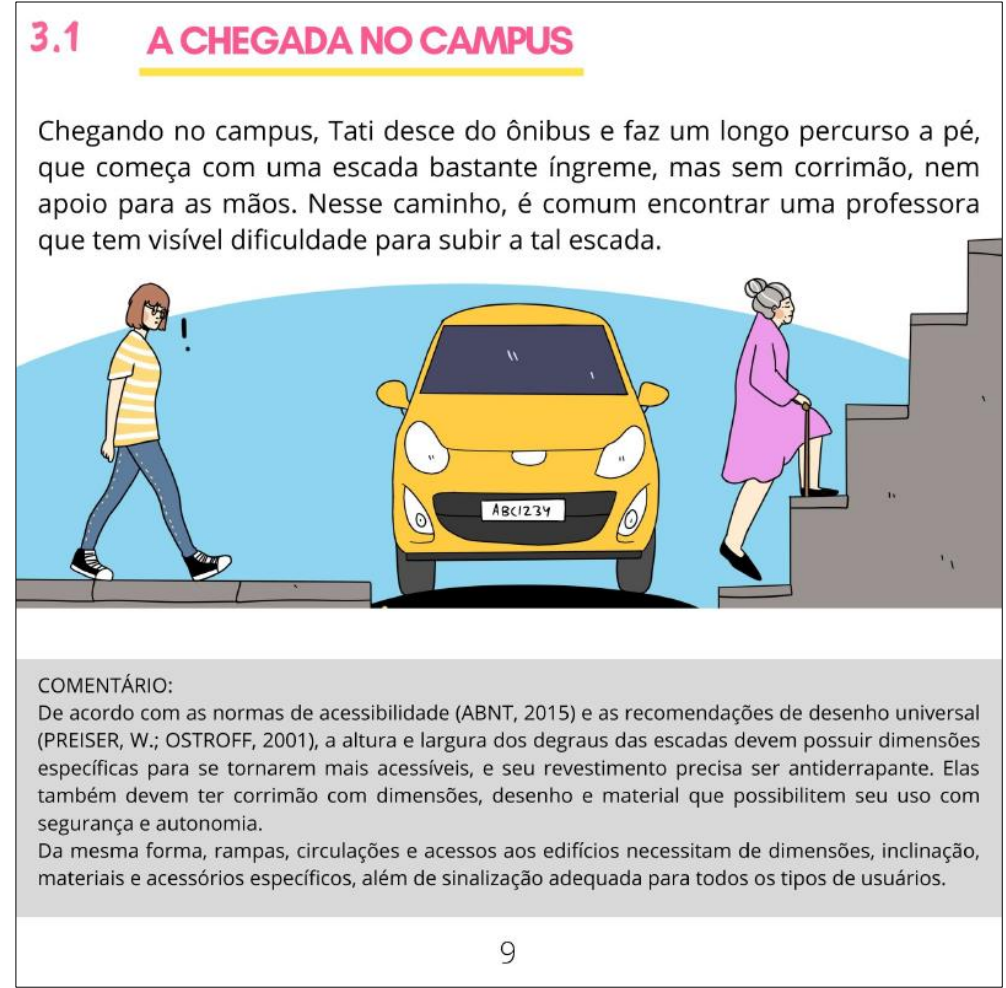

Fonte: Lima et al, 2020

\section{PRINCIPAIS TEMÁTICAS TRATADAS}

Os assuntos tratados foram subdivididos em 07 temas relacionados à vivência cotidiana dos usuários de campi (Figura 3), como sejam: a chegada ao local (que geralmente acontece por meio de transporte coletivo), as salas de aulas, o restaurante, os laboratórios, a biblioteca, as atividades noturnas na área do campus e a volta para casa. 


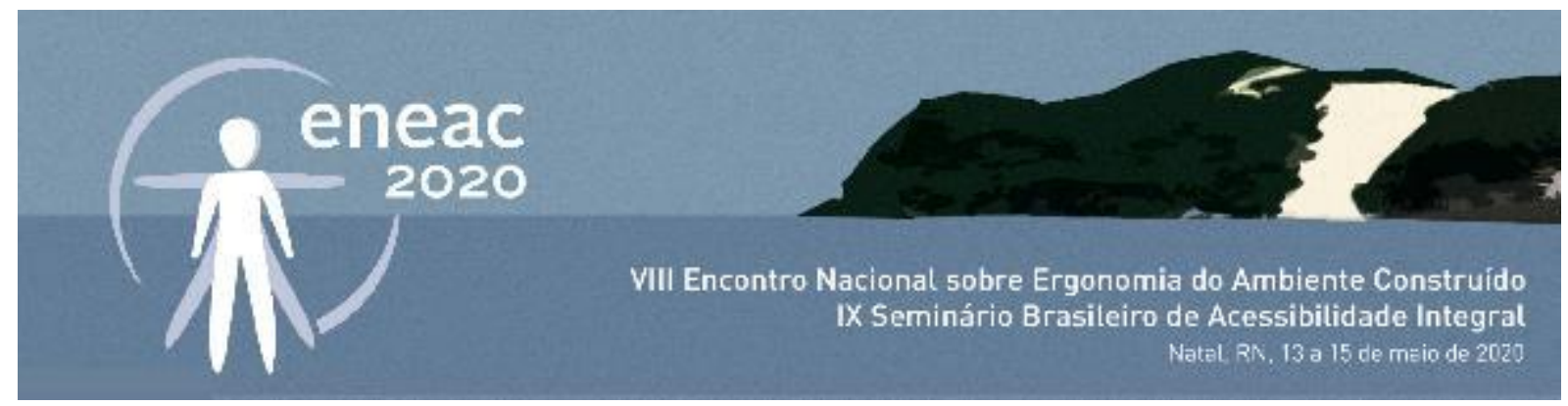

Figura 3: Sumário da cartilha

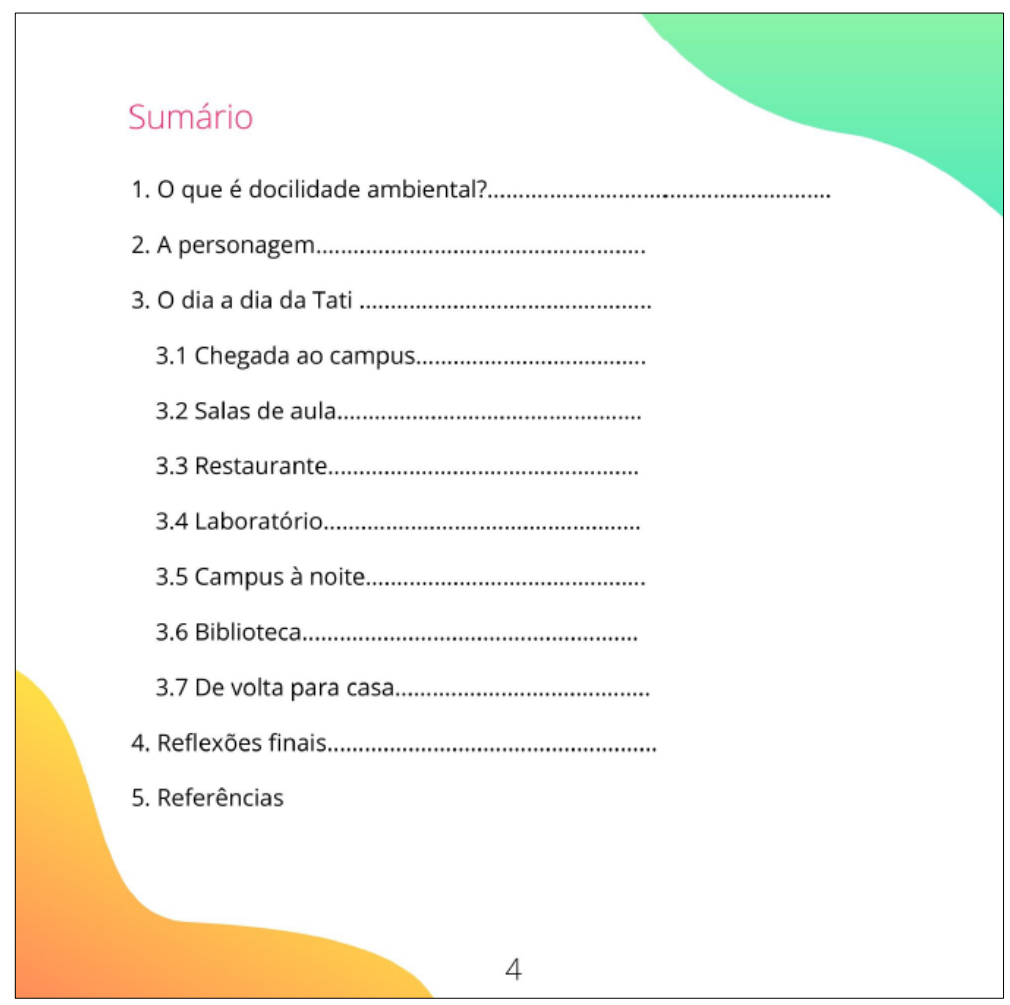

Fonte: Lima et al, 2020.

Nesse contexto, é preciso ressaltar que, a cada tipo de situação relatada podem ser associados diversos camadas de questões (Figuras 4 e 5). Assim, por exemplo, no que diz respeito à sala de aula são tratados assuntos relacionados a, entre outros: mobiliário, layout e circulação interna no cômodo, visibilidade da lousa (ou do local para projeção, no caso de aulas com uso de projetor de imagens) e condições acústicas.

Como exemplo dessa mistura de informações, observa-se que uma situação considerada relativamente simples, como a dificuldade de uma pessoa enxergar algo escrito no quadro ou de ouvir a explicação do professor, pode envolver inúmeros aspectos, tais como:

- o layout da sala (arranjo físico do mobiliário);

- a posição especificamente ocupada pelo indivíduo que apresenta aquele tipo de dificuldade (se posicionando dentro do cone de melhor visualização ou audição ou fora dele);

- as características do material didático utilizado pelo professor/a;

- o comportamento dos demais estudantes ali presentes, inclusive no que diz respeito às condições acústicas (maior ou menor barulho) em classe. 


\section{eneac}

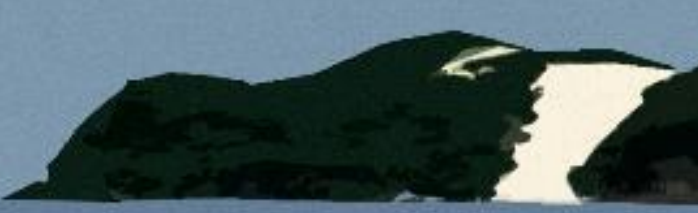

VIII Encontro Nacional sobre Ergonomia do Ambiente Construido IX Seminário Brasileiro de Acessibilidade Integral

Figura 4 e 5: Duas páginas relacionadas à sala de aula (conforme exemplo indicado no texto)

\subsection{SALAS DE AULA}

Já na sala de aula, Tati observa que seu colega Lucas está piscando muito e apertando os olhos em direção

ao quadro, esforçando-se para compreender o conteúdo.
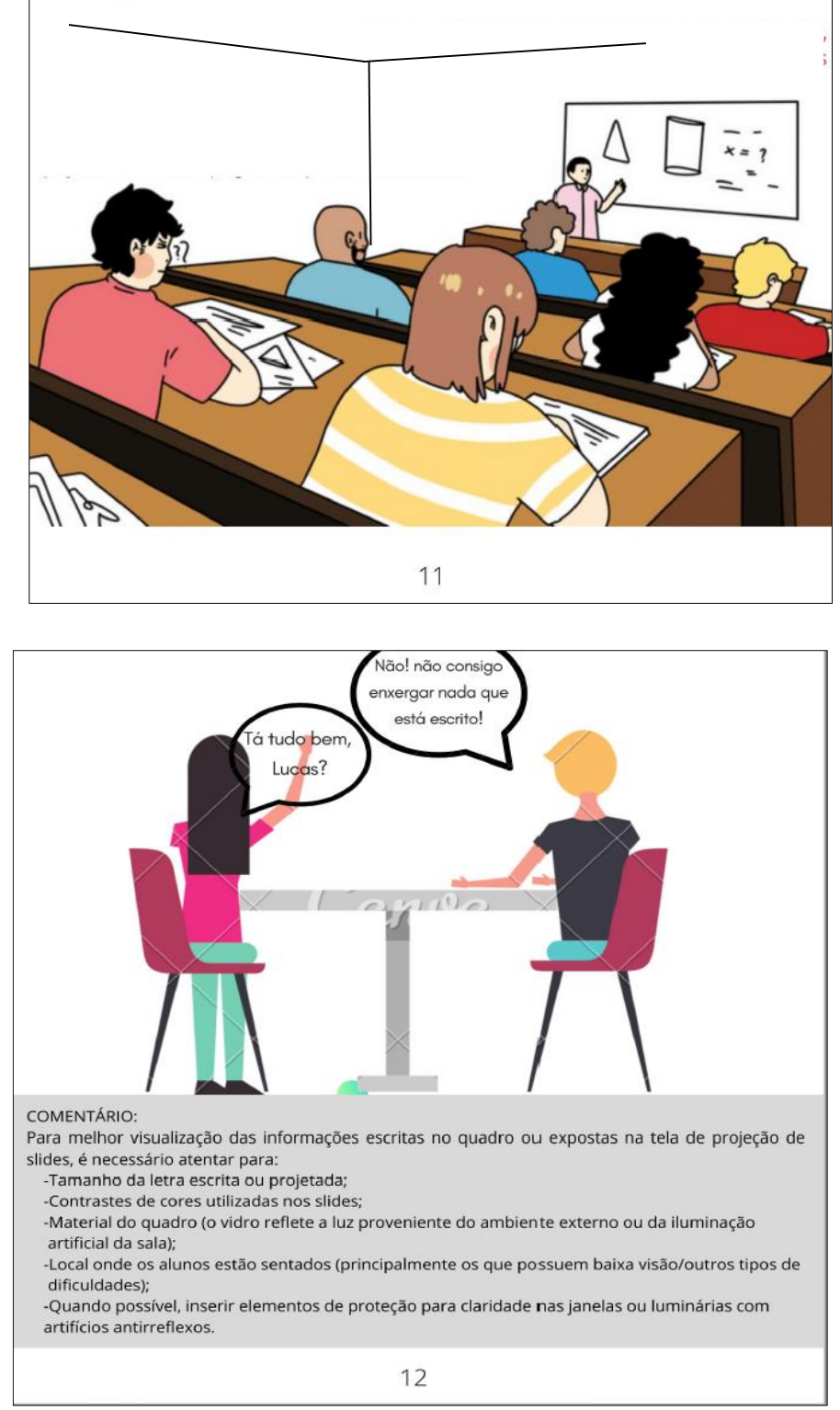

Fonte: Lima et al, 2020. 


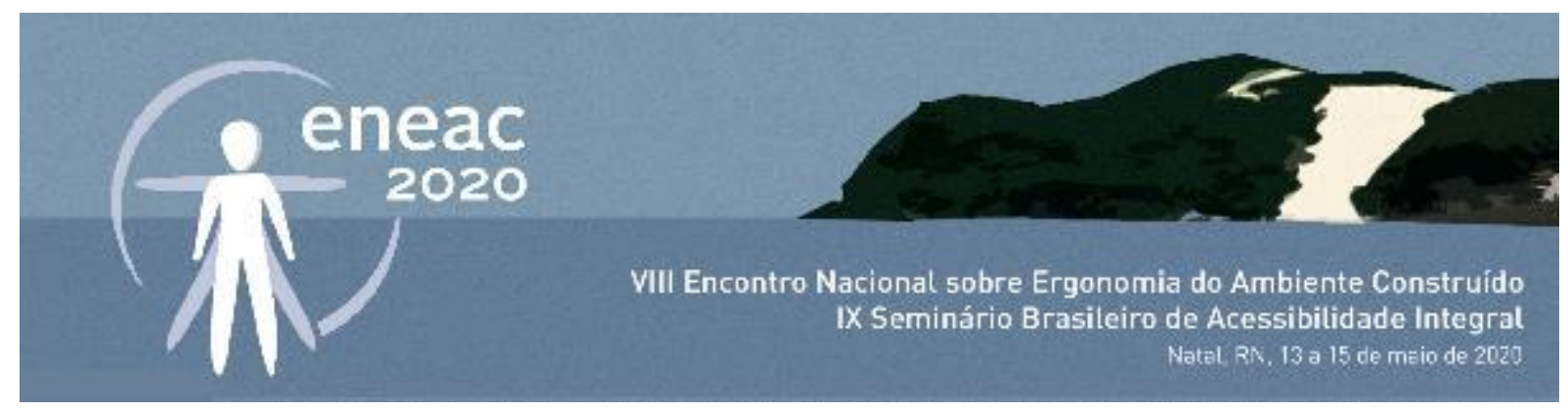

É fundamental destacar que, no decorrer da cartilha, cada página foi planejada como um conjunto (composto pelos elementos que caracterizam uma situação somados às diversas informações a serem consideradas para compreendê-la). Sob essa perspectiva, cada quadro apresentado tem como principal meta mostrar ao leitor que a docilidade ambiental tanto é fruto das condições objetivas do ambiente físico, quanto está ligada às atitudes e comportamentos do grupo envolvido (quer sejam parte da rede de apoio social àquela pessoa em especial, quer caracterizem a sua omissão ou indiferença perante a situação ali vivenciada).

\section{CONSIDERAÇÕES FINAIS}

Os estudos realizados por nosso grupo (pesquisas de professores, trabalhos de bolsistas de iniciação científica (IC), dissertações ou teses desenvolvidas nos Programas de Pós-Graduação em Arquitetura e Urbanismo e em Psicologia da UFRN) têm indicado a necessidade de todos nos envolvermos com a docilidade ambiental do campus, promovendo condições de acessibilidade integral nas mais diversas situações cotidianas. A cartilha apresentada nesse paper tentou traduzir esse entendimento e transformar indicações pontuais em elementos a serem discutidos coletivamente - se conseguirmos fomentar esse debate teremos atingido nossos objetivos.

Certamente parte das questões a enfrentar corresponde à qualidade do espaço físico (salubridade, acessibilidade, dimensionamento, ergonomia do mobiliário) - nesses casos, as soluções passam pela identificação dos problemas e, quando for o caso, pela reivindicação de melhorias. No entanto, outra importante parte dos problemas diz respeito ao modo das pessoas entenderem e tratarem umas às outras, sobretudo aqueles indivíduos com maiores dificuldade para enfrentar situações adversas (sejam elas pessoas com deficiência, sejam pessoas com dificuldades ocasionais de pequeno, médio ou grande porte). Nesses casos, a construção de redes de apoio é essencial, e todos podemos fazer parte da solução: ajudar a carregar livros, ceder a carteira em local mais favorável para alguém com maiores dificuldades perceptivas ou cognitivas, preparar material didático mais facilmente visualizável, são ações que parecem ser simples, mas que podem trazer melhorias para o dia-a-dia de todos.

Também é preciso chamar a atenção para a importância de cada pessoa ser mais compreensível e dócil consigo mesmo, tentando manter horários coerentes para descanso e alimentação, garantir tempos para relaxamento e lazer entre jornadas, buscar materiais e moveis que atendam necessidades ergonômicas e promovam conforto.

Concluindo, no campo da acessibilidade integral, a docilidade ambiental é um ideal de qualidade a ser atingido coletivamente, e não apenas nos campi; ela precisa ser procurada em todos os lugares que frequentamos: em casa, no trabalho, no lazer... Cabe a cada um contribuir para tornar o ambiente mais dócil a si mesmo e aos outros. Elaborar a cartilha aqui brevemente apresentada foi um dos meios que encontramos para difundir o conhecimento que temos acumulado nesse campo e promover o debate sobre o tema. 


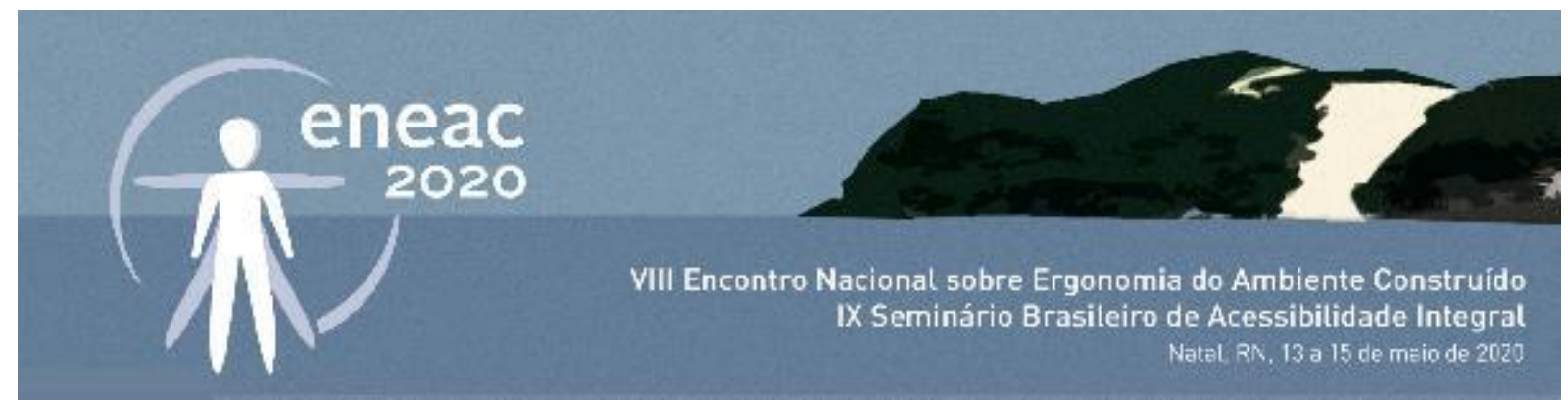

\section{AGRADECIMENTOS}

Nossos sinceros agradecimentos:

- à Universidade Federal do Rio Grande do Norte, em especial à Secretaria de Inclusão e Acessibilidade (SIA) e ao Prof. Dr. Francisco Ricardo Lins Mel, pelo apoio institucional;

- a bolsa de Iniciação Científica (IC) da primeira autora;

- a bolsa de produtividade em pesquisa (CNPq) da última autora.

\section{REFERÊNCIAS}

ASSOCIAÇÃO BRASILEIRA DE NORMAS TECNICAS (ABNT). NBR 9050/2015 - Acessibilidade a edificações, mobiliário, espaços e equipamentos urbanos. Rio de Janeiro: ABNT, 2015.

CAVALCANTE, S.; ELALI, G. A. (Orgs.). Temas básicos em Psicologia Ambiental. Petrópolis: Vozes, 2011.

CAVALCANTE, S.; ELALI, G. A. (Orgs.). Psicologia Ambiental: conceitos para a leitura das relações pessoa-ambiente. Petrópolis: Vozes, 2018.

DUARTE, C. R.; COHEN, R. A acessibilidade como fator de construção do lugar. In: A. R. A. PRADO; M. E. LOPES; S. W. ORNSTEIN (Orgs), Desenho universal: os caminhos da acessibilidade no Brasil. São Paulo: Anna Blume, 2010, pp. 8194.

ELALI, G. V. M. A.; ARAUJO, R. G. ; PINHEIRO, J. Q. . Acessibilidade Psicológica: eliminar barreiras 'físicas' não é suficiente. In: A. A. R. PRADO; M. E. LOPES; S. W. ORNSTEIN. (Org.). Desenho Universal: caminhos da acessibilidade no Brasil. São Paulo: AnnaBlume, 2010, pp. 117-127.

GÜNTHER, I. Pressão ambiental (Environmental Press). In: S. CAVALCANTE; G. A. ELALI (Orgs.). Temas básicos em Psicologia ambiental. Petrópolis: Vozes, 2011, pp. 290-295

GÜNTHER, I.; ELALI, G. A. Docilidade ambiental. In: S. CAVALCANTE; G. A. ELALI (Orgs.). Psicologia Ambiental: conceitos para compreensão das relações pessoa-ambiente. Petrópolis: Vozes, 2018, p. 47-59.

GÜNTHER, H.; PINHEIRO, J. Q.; GUZZO, R. S. L. (Orgs.). Psicologia ambiental: entendendo as relações do homem com seu ambiente. Campinas: Alínea, 2004.

LAWTON, M. P.; DEVOE, M. R.; PARMELEE, P. Relationship of events and affect in the daily life of an elderly population. Psychology and Aging, 10, 1995, pp. 469-477.

LAWTON, M. P.; NAHEMOW, L. Ecology and the aging process. In C. EISDORFER; M. P. LAWTON (Eds.), The psychology of adult development and aging. Washington, DC: American Psychological Association, 1973, s/p

LIMA, C. T.; AZEVEDO, J.; MEDEIROS, L.; MEDEIROS, R.; ELALI, G. A. Docilidade ambiental em campus - cartilha de sensibilização (e-book)..Natal: EdUFRN, 2020.

MOORE, K. D. Using place rules and affect to understand environmental fit: A theoretical exploration. Environment and Behavior 37, 2005, pp. 330-363.

PINHEIRO, J. Q.; GÜNTHER, H. (Orgs.). Métodos de pesquisa nos estudos pessoa-ambiente. São Paulo: Casa do Psicólogo, 2008.

PREISER, W.; OSTROFF, E. Universal Design Handbook. New York: McGraw-Hill, 2001. 